\title{
Therapeutic Response of Mifepristone with Dinoprost and Misoprostol for Management of Canine Pyometra
}

\author{
Pratyush Kumar, S.N. Shukla, Krishna Kumar, Tushar Thakre, O.P. Shrivastava
}

10.18805/IJAR.B-4381

\begin{abstract}
Background: Canine pyometra (chronic purulent endometritis) is one of the most important uterine disorder of bitches seeks medical treatment. The hormonal therapies are not much popular among the veterinarians thus needs to exploit some hormonal protocols for this condition. Therefore, the experiment was carried out to study the therapeutic response of antiprogestin and prostaglandin in canine pyometra.

Methods: The experiment was carried out in total 21 bitches affected with pyometra were selected and divided randomly into 3 groups. Animals of control group $\left(T_{C}\right)$ were treated with non-hormonal supportive treatment for 7 days. Animals of $T_{1}$ were received non-hormonal supportive treatment for 7 days similar to $T_{C}$ along with mifepristone @ $3 \mathrm{mg} / \mathrm{kg}$ orally BID on day 1,2 and 8 and Dinoprost in @ 50-200 mcg/kg S/C day 3 to 7 . Animals of $T_{2}$ were treated similar to $T_{C}$ plus mifepristone @ $3 \mathrm{mg} / \mathrm{kg}$ orally BID on day 1,2 and 8 and Misoprostol @ $3 \mathrm{mcg} / \mathrm{kg}$ intravaginally twice daily on day 3 to 7.

Result: Therapeutic responses was recorded better in $T_{1}$ group (100\%), followed by $T_{2}(71.43 \%)$ and $T_{C}(42.86 \%)$. The mean TLC values after completion of treatment (day 8) were significantly decreased in $T_{1}$ and $T_{2}$. The neutrophil count in different groups $T_{1}$, $T_{2}$ and $T_{C}$ was reduced significantly. There was significant decrease in mean concentration of BUN and creatinine on day 8 after treatment in $T_{1}$ and $T_{2}$ groups. The mean ALT values decreased significantly in $T_{1}$ group. However, ALP values decreased significantly in $T_{1}$ and $T_{2}$ groups. The mean serum progesterone declined significantly in both the hormone treated groups $\left(T_{1}\right.$ and $\left.T_{2}\right)$. The study can be concluded that therapeutic response of mifepristone with dinoprost tromethamine was found most effective for the treatment of canine pyometra than mifepristone with misoprostol protocol.
\end{abstract}

Key words: Antiprogestin, Biochemical profile, Canine, Prostaglandin, Pyometra.

\section{INTRODUCTION}

Pyometra is a uterine disorder that usually occurs during diestrum in intact adult females, characterized with the accumulation of purulent material within the uterine lumen by an inflammatory exudate and uterine bacterial colonization associated with cystic endometrial hyperplasia $(\mathrm{CEH})$. Usually pyometra occurs during the luteal phase following estrus although anestrus bitches also can be diagnosed with pyometra (Noakes et al., 2001; Lopate, 2017). Progesterone results in endometrial proliferation, uterine glandular secretion, decreased myometrial contraction and induce closure of the cervix (Smith, 2006). Common bacteria found in the uteri of healthy bitches reflect the bacterial flora of the vagina and cervix. Escherichia coli is the pathogen most commonly isolated from bitches with pyometra (Hagman and Kuhn, 2002; Hagman et al., 2006; Kirby, 2017). The hematological and biochemical abnormalities commonly found during the disease are leukocytosis with neutrophilia, elevated blood urea nitrogen (BUN), creatinine, alanine aminotransferase (ALT) and Alkaline phosphatase (ALP) levels.

As progesterone was found to be a major role in inducing cystic endometrial hyperplasia-pyometra complex, hence antiprogestin such as mifepristone could be expected to be useful in a medical treatment protocol. The molecule has been effectively suppressing the biological
College of Veterinary Science and Animal Husbandry, Nanaji Deshmukh Veterinary Science University, Jabalpur-482 001, Madhya Pradesh, India.

Corresponding Author: Pratyush Kumar, College of Veterinary Science and Animal Husbandry, Nanaji Deshmukh Veterinary Science University, Jabalpur-482 001, Madhya Pradesh, India.

Email: pratyushvci@gmail.com

How to cite this article: Kumar, P., Shukla, S.N., Kumar, K., Thakre, T. and Shrivastava, O.P. (2021). Therapeutic Response of Mifepristone with Dinoprost and Misoprostol for Management of Canine Pyometra. Indian Journal of Animal Research.

DOI: 10.18805/IJAR.B-4381.

Submitted: 16-12-2020 Accepted: 28-07-2021 Online: 21-08-2021

action of progesterone during gestation, interrupting gestation, causing cervical opening and induces parturition (Fieni, 2006). Progesterone blockers suggested being of special interest for pyometra treatment in canine especially of closed pyometra (Fieni, 2006). In fact, the use of an antiprogestin (aglepristone and mifepristone) in combination with PGF $_{2 \alpha}$ was reported highly effective (Fieni, 2006). To improve efficacy, mifepristone is currently used in combination with low doses of prostaglandin analogues. Therefore, present study was carried out to prove the effect of antiprogestin and prostaglandins in canine pyometra. 


\section{MATERIALS AND METHODS}

\section{Ethical approval}

All the procedures of this experiment were approved by the committee of ethics for research of College of Veterinary Science and Animal Husbandry, Jabalpur, MP, India.

\section{Study plan}

Total number of 21 clinical cases of canine pyometra with good general health irrespective of breed and age were used for the study. Animals having history of anorexia, abnormal vaginal discharge, polyuria, polydipsia and vomition (sometimes) were tentatively considered cases of uterine disorders. However, pyometra was further confirmed by ultrasonographic examination reveals presence of pus pockets or endometrial hyperplasia.

The selected 21 bitches affected with pyometra were divided randomly into 3 groups. Animals of first treatment group $\left(T_{1}\right)$ were treated with non-hormonal supportive treatment for 7 days along with mifepristone @ $3 \mathrm{mg} / \mathrm{kg}$ orally twice daily on day 1,2 and 8 and Dinoprost tromethamine in a progressively increasing dose @ 50-200 $\mathrm{mcg} / \mathrm{kg}$ subcutaneously once daily from day 3 to 7 (d-3 : $50 \mathrm{mcg} / \mathrm{kg}, \mathrm{d}-4: 100 \mathrm{mcg} / \mathrm{kg}, \mathrm{d}-5: 150 \mathrm{mcg} / \mathrm{kg}$, d-6 and d$7: 200 \mathrm{mcg} / \mathrm{kg})$. Animals of second treatment group $\left(T_{2}\right)$ were treated with non-hormonal supportive treatment for 7 days along with mifepristone @ $3 \mathrm{mg} / \mathrm{kg}$ orally twice daily on day 1,2 and 8 and Misoprostol @ $5 \mathrm{mcg} / \mathrm{kg}$ intravaginally twice daily from day 3 to 7 . Animals of control group $\left(T_{c}\right)$ were received only non-hormonal supportive treatment for 7 days.

Following start of treatment, the animals were daily examined clinically to evaluate treatment response in terms of activity, appetite and vulvar discharge. The assessment of uterine distention was confirmed by ultrasonography on day 7 and 14 and day 21 . The blood samples were collected on day 0 (before treatment) and day 8 (after treatment). Various haemato-biochemical parameters were estimated by standard methods.

\section{RESULTS AND DISCUSSION}

Therapeutic responses for recovery of pyometra was recorded better in $\mathrm{T}_{1}$ group (100\%), followed by $\mathrm{T}_{2}(71.43 \%)$ and $\mathrm{T}_{\mathrm{C}}(42.86 \%)$. The repeated administration of prostaglandin analogues significantly increased the success rate at day 8 of treatment. The uterotonic action of prostaglandin analogues (dinoprost and misoprostol) lead to a faster decrease in the diameter of uterine lumen and its luteolytic action caused a faster drop in mean plasma progesterone concentration as compared to effect of non-hormonal therapeutic medication in animals. Among both prostaglandins, dinoprost showed the better therapeutic response in canine pyometra as compared to misoprostol treated animals. However, side effects of prostaglandin $\mathrm{F}_{2 \alpha}$ viz. vomiting, salivation, loose faeces, urination, ataxia, hyperpnoea and constriction or dilatation of pupil were seen similar to the previous report of Jena et al. (2013). As described before, side effects may be reduced and eliminated by walking the dog after the injection of PGF ${ }_{2 a}$ (Lopate, 2017).

All the characteristic clinical signs of pyometra like vaginal discharge, polydipsia, polyuria, depression and anorexia disappeared by day $8^{\text {th }}$ of therapy indicating complete clinical recovery. Further, recovery was accompanied by a gradual decrease in the diameter of the uterine lumen which became non-detectable ultrasonographically (Plate 3 and 4). The mean decrease in the diameter of the uterine lumen decreased gradually depends on treatment used (Table 1) which was significantly greater among days 0,7 and 14 in bitches receiving the combined mifepristone-dinoprost treatment than in those treated with mifepristone-misoprostol and non-hormonal (100\% versus $71.43 \%$ and $42.86 \%$ ).

Effect of different treatment regimens on total uterine diameter and endometrium thickness in dogs affected with pyometra

On ultrasonographic examination, the mean total uterine diameter $(\mathrm{mm})$ on day 0 was measured as $27.25 \pm 2.63$ in $\mathrm{T}_{1}, 28.13 \pm 2.78$ in $\mathrm{T}_{2}$ and $29.40 \pm 3.62$ in $\mathrm{T}_{\mathrm{C}}$ treatment groups. There was significantly decrease in mean values of total uterine diameter in all the groups over the period of time from day 0 to day 14 (Plate 3 and 4). However, it decreased significantly $(p<0.01)$ faster (on day 7$)$ in both the hormonal treated groups $\left(T_{1}\right.$ and $T_{2}$ ) as compared to non-hormonal treatment (Tc) group. Similar results on uterine diameter were also reported using different treatment in canine pyometra by Renukaradhya (2011) and Meher et al. (2018). The several studies supporting the procedure adopted in this study for the confirmation of pyometra as the diagnosis of pyometra is best made with the aid of ultrasonography (Bigliardi et al., 2004) and findings typically include an enlarged uterus with convoluted, tubular horns filled with anechoic to hypoechoic fluid (Plate 1) (Fayrer-Hosken et al., 1991 and Voges et al., 1996). The luminal contents are usually homogenous but contents may also be echodense with slow, swirling patterns (Nyland and Matton 2002).

Table 1: Effect of different treatment regimens on total uterine diameter in dogs affected with pyometra.

\begin{tabular}{ccccc}
\hline Parameters & Group & Day 0 & Day 7 & Day 14 \\
\hline Total uterine diameter $(\mathrm{mm})$ & $\mathrm{T}_{1}$ & $27.25^{\mathrm{a}} \pm 2.63$ & $11.37^{\mathrm{b}} \pm 1.64$ & not detected \\
& $\mathrm{T}_{2}$ & $28.13^{\mathrm{a}} \pm 2.78$ & $13.81^{\mathrm{b}} \pm 2.16$ & $12.92 \pm 2.05(2 \mathrm{cases})$ \\
Endometrial thickness $(\mathrm{mm})$ & $\mathrm{T}_{\mathrm{C}}$ & $29.40 \pm 3.62$ & $18.54 \pm 4.07$ & $14.77 \pm 4.32(4 \mathrm{cases})$ \\
& $\mathrm{T}_{1}$ & $4.13 \pm 0.84$ & $1.39 \pm 0.34$ & not measurable \\
& $\mathrm{T}_{2}$ & $5.09 \pm 0.43$ & $2.66 \pm 0.18$ & $1.27 \pm 0.22(2 \mathrm{cases})$ \\
& $\mathrm{T}_{\mathrm{C}}$ & $6.04 \pm 0.95$ & $3.36 \pm 0.50$ & $1.81 \pm 0.46(4 \mathrm{cases})$ \\
\hline
\end{tabular}


A thickened endometrium with cystic structures is diagnostic for CEH (Plate 2) with or without pyometra (Voges et al., 1996).

The mean endometrium thickness of uterus of pyometric dogs was measured by ultrasonography on day 0,7 and 14 as shown in Plate 2. The mean values of endometrium thickness $(\mathrm{mm})$ was ranged $4.13 \pm 0.84$ to $6.04 \pm 0.95$ before start of treatment (day 0 ) in all the groups. Later on it gradually decreased over the period of treatment (day 7 and 14) in all groups. In recovered animals, it was difficult to detect uterus so endometrium thickness couldn't be measurable $(<1 \mathrm{~mm})$ in ultrasonography. The ultrasonographic aspect of a pathologically altered uterus varies but luminal fluid is commonly found and ultrasound is of great use to detect mild accumulation of fluid, even if differentiation of the type of fluid is not feasible (Pollard and Hecht, 2015).

All hematological parameters like total leukocyte count, neutrophil count, BUN, creatinine, Alanine aminotransferase (ALT), Alkaline phosphatase (ALP) and serum progesterone concentration elevated before treatment were decreased to normal range in completely recovered animals of different treatment groups (Table 2).

The mean TLC values $\left(10^{3} / \mu \mathrm{l}\right)$ recorded before initiation of treatment (day 0 ) were $34.81 \pm 2.73,30.90 \pm 3.47$ and $32.75 \pm 3.69$, respectively in $T_{1}, T_{2}$ and $T_{C}$ groups. These values were highly elevated as compared to the normal physiological range $\left(6-17 \times 10^{3} / \mu \mathrm{l}\right)$. However, decrease in the mean TLC values after completion of treatment (day 8) were significantly decreased in $T_{1}$ and $T_{2}$ however, difference was statistically non significant in control group. There is availability of ample literature for support of the study. The comparable results of mean TLC values in canine pyometra were reported by Renukaradhya (2011) and Melih et al. (2012) i.e. $24.05 \pm 59$ to $51.24 \pm 80 \times 10^{3}$ per $\mathrm{cmm}$ and $38.53 \pm 7.28 \times 10^{3}$ per $\mathrm{cmm}$, respectively. However, comparatively low TLC was found in the study of Fransson et al (2007) and Hagman et al. (2006) who reported mean values of $22.6 \pm 13.5 \times 10^{3}$ per $\mathrm{cmm} ; 23.31 \pm 11.45 \times 10^{3}$ per $\mathrm{cmm}, 22.8 \pm 11.4 \times 10^{3}$ per $\mathrm{cmm}$, respectively.

The systemic effects of pyometra are reflected in the hemato-biochemical parameters of the animals. A characteristic change in the leukogram of the animal is noticed with significant increase in total leucocyte count (Bigliardi et al., 2004). A common pathologic clinical finding in bitches with pyometra is a peripheral leukocytosis which is more pronounced in closed-cervix pyometra (Gandotra et al., 1994). The marked leucocytosis observed in cases of pyometra is suggested to be due to bone marrow inflammatory response (Sevelius et al., 1990) and diffused suppurative inflammation of uterus to combat the infection. The mean neutrophils (\%) on day 0 was recorded $80.17 \pm$ 1.59 in $T_{1}, 76.96 \pm 1.40$ in $T_{2}$ and $77.10 \pm 1.46$ in $T_{C}$ groups. The results are similar to previous reports of Hoffmann et al. (2000), Trasch et al. (2003) and Fieni (2006). After treatment the mean values of neutrophils returned to normal physiological values in all treated groups i.e., $67.86 \pm 0.96$ in $\mathrm{T}_{1}, 69.76 \pm 0.73$ in $\mathrm{T}_{2}$ and $71.76 \pm 1.45$ in $\mathrm{T}_{\mathrm{C}}$ groups. The leucocytosis which is a predominant finding in the study is due to neutrophilia exhibited by most of the animals.

Table 2: Haematological, haematobiochemical and progesterone hormone profiles before and after treatment in dogs affected with pyometra.

\begin{tabular}{|c|c|c|c|}
\hline Parameters & Group & Day 0 & Day 8 \\
\hline \multirow[t]{3}{*}{ Total Leukocyte Count (TLC) $\left(10^{3} / \mu \mathrm{l}\right)$} & $\mathrm{T}_{1}$ & $34.81^{\mathrm{a}} \pm 2.73$ & $12.72^{b} \pm 0.83$ \\
\hline & $\mathrm{T}_{2}$ & $30.90^{\mathrm{a}} \pm 3.47$ & $18.10^{\mathrm{b}} \pm 2.07$ \\
\hline & $T_{C}$ & $32.75 \pm 3.69$ & $25.20 \pm 4.19$ \\
\hline \multirow[t]{3}{*}{ Neutrophil count (\%) } & $\mathrm{T}_{1}$ & $80.17^{a} \pm 1.59$ & $67.86^{b} \pm 0.96$ \\
\hline & $\mathrm{T}_{2}$ & $76.96^{\mathrm{a}} \pm 1.40$ & $69.76^{\mathrm{b}} \pm 0.73$ \\
\hline & $T_{C}$ & $77.10^{A} \pm 1.46$ & $71.76^{B} \pm 1.45$ \\
\hline \multirow[t]{3}{*}{ BUN (mg/dl) } & $\mathrm{T}_{1}$ & $34.28^{a} \pm 3.40$ & $15.93^{b} \pm 2.33$ \\
\hline & $\mathrm{T}_{2}$ & $39.07^{a} \pm 2.50$ & $21.92^{\mathrm{b}} \pm 1.66$ \\
\hline & $\mathrm{T}_{\mathrm{C}}$ & $34.27 \pm 4.95$ & $26.76 \pm 3.50$ \\
\hline \multirow[t]{3}{*}{ Creatinine $(\mathrm{mg} / \mathrm{dl})$} & $\mathrm{T}_{1}$ & $1.897^{\mathrm{a}} \pm 0.145$ & $1.027^{b} \pm 0.124$ \\
\hline & $\mathrm{T}_{2}$ & $1.886^{\mathrm{a}} \pm 0.095$ & $1.286^{b} \pm 0.099$ \\
\hline & $\mathrm{T}_{\mathrm{C}}$ & $2.053 \pm 0.328$ & $1.756 \pm 0.337$ \\
\hline \multirow[t]{3}{*}{ Alanine aminotransferase (ALT) (IU/L) } & $\mathrm{T}_{1}$ & $69.53^{a} \pm 6.25$ & $34.46^{b} \pm 4.03$ \\
\hline & $\mathrm{T}_{2}$ & $60.50 \pm 7.07$ & $44.77 \pm 3.65$ \\
\hline & $\mathrm{T}_{\mathrm{C}}$ & $52.20 \pm 8.23$ & $48.7 \pm 7.63$ \\
\hline \multirow[t]{3}{*}{ Alkaline phosphatase (ALP) (IU/L) } & $\mathrm{T}_{1}$ & $117.91^{\mathrm{a}} \pm 2.31$ & $60.52^{b} \pm 3.67$ \\
\hline & $\mathrm{T}_{2}$ & $125.50^{\mathrm{a}} \pm 12.4$ & $93.25^{\mathrm{b}} \pm 9.09$ \\
\hline & $T_{C}$ & $127.05 \pm 5.45$ & $98.02 \pm 6.19$ \\
\hline \multirow[t]{3}{*}{ Serum progesterone concentration $(\mathrm{ng} / \mathrm{ml})$} & $\mathrm{T}_{1}$ & $11.56^{\mathrm{a}} \pm 0.941$ & $1.63^{b} \pm 0.258$ \\
\hline & $\mathrm{T}_{2}$ & $11.99^{\mathrm{a}} \pm 1.17$ & $3.08^{b} \pm 0.674$ \\
\hline & $\mathrm{T}_{\mathrm{C}}$ & $11.48 \pm 0.844$ & $7.26 \pm 0.910$ \\
\hline
\end{tabular}

${ }^{*}$ Mean values with different superscripts (a and b) in a row differs significantly $(p<0.01)$. 
Neutrophilia has also been reporded in several studies (Hagman et al., 2006; Renukaradhya, 2011 and Arunima, 2013). It might be due to retention of purulent exudates in the uterus which exerts a chemotactic effect on neutrophils resulting into accelerated granulopoiesis (Meher et al., 2018). The neutrophilia recorded in the present investigation may be attributed to the defense mechanism of the uterus in response to the invading microorganisms.

In present study BUN $(15.93 \pm 2.33 \mathrm{mg} / \mathrm{dl})$ in Dinoprost treated animals on day 8 was similar to the findings of Shah et al. (2016) on day 14. The mean BUN value of control group $\left(\mathrm{T}_{\mathrm{C}}\right)$ on day 8 was similar to that of Jena et al. (2013). Renukaradhya (2011) and Jena et al. (2013) reported comparatively low mean values of BUN (12.88 \pm 0.89 to 26.38 $\pm 7.44 \mathrm{mg} / \mathrm{dl}$ ) on day 0 . In other study Shah et al. (2016) had reported slight elevated mean values of BUN (46.01 \pm 3.29 to $46.69 \pm 1.43 \mathrm{mg} / \mathrm{dl}$ ) on day 0 . This variation may be due to individual variation in severity of case, age group and physio-pathological condition of multiple organs especially kidney. Wheaton et al. (1989) concluded that elevated blood urea nitrogen level seen in some cases in their study was most often a result of pre renal uremia. The pre renal factors are those which lead to the lowering of glomerular filtration rate and impair the efficiency of kidneys. A gradual decrease in elevated blood urea nitrogen level during the course of treatment is indicative of positive response of the animal to the treatment and elimination of toxaemia in the affected bitches. This reversal of toxemia was consistent with other studies (Verstegen et al., 2008).

The mean creatinine value in this study decreased significantly on day 8 in hormonal treated groups. However, difference in control ( $T_{C}$ ) group was statistically not significant. Similar results were also reported by

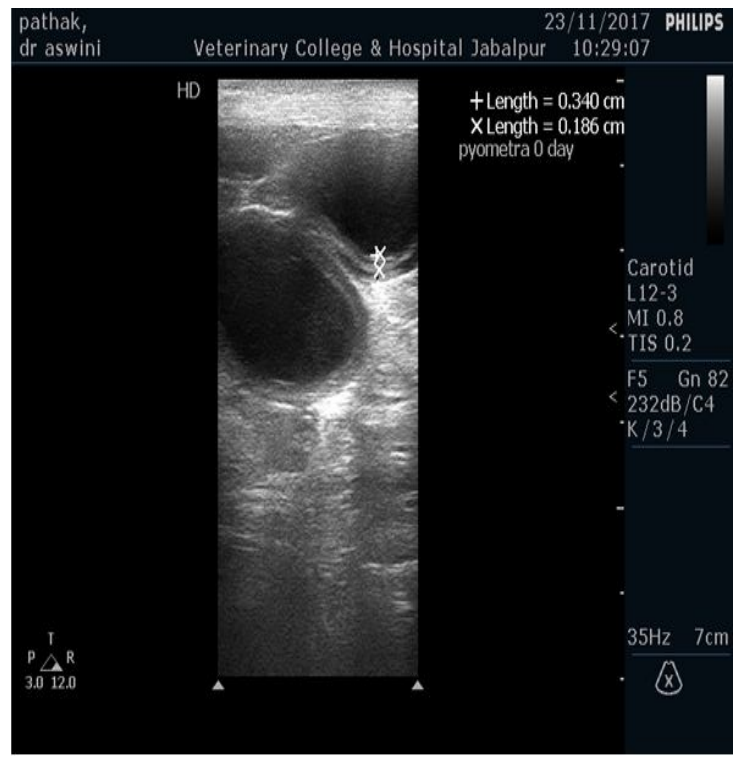

Plate 1: Ultrasonograph of the caudal abdomen of a bitch showing pus pockets in uterus.
Renukaradhya (2011). The present findings are in agreement with the findings of Lopate (2017) who also reported a slight increase in the creatinine level above the normal range in few animals in different treatment groups. It could be attributed to reduced renal perfusion relating to toxemia. The impairment of renal function along with other multiple organ dysfunctions is a frequent complication of pyometra (Hiene et al., 2001 and Lopate, 2017). However, in some studies no significant variation in mean creatinine values in animals with pyometra in different treatment groups on day 0 and 8 was recorded and it remains in the

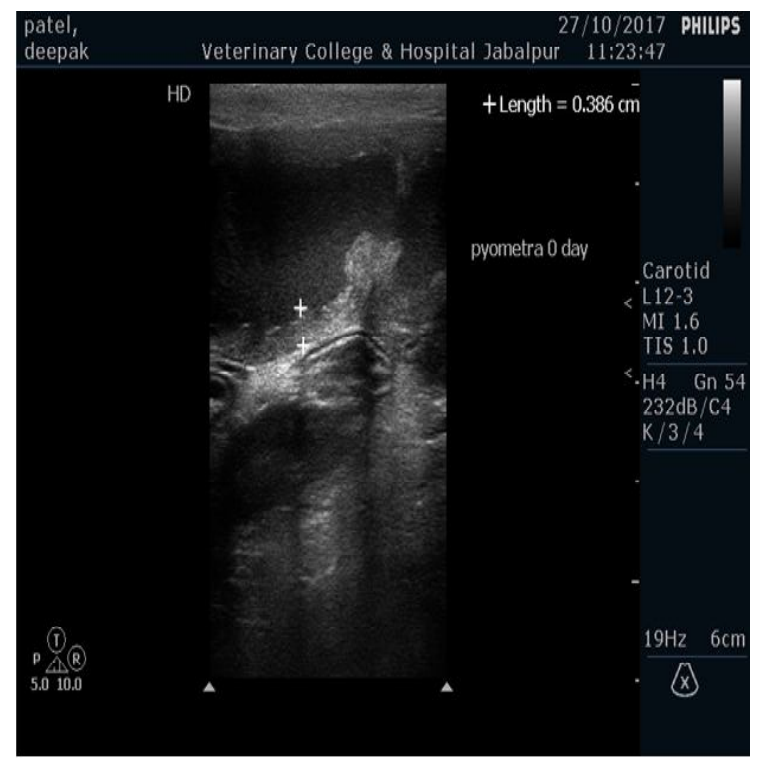

Plate 2: Ultrasonograph of caudal abdomen of a bitch showing pus filled uterus and hyperplasia of endometrium.

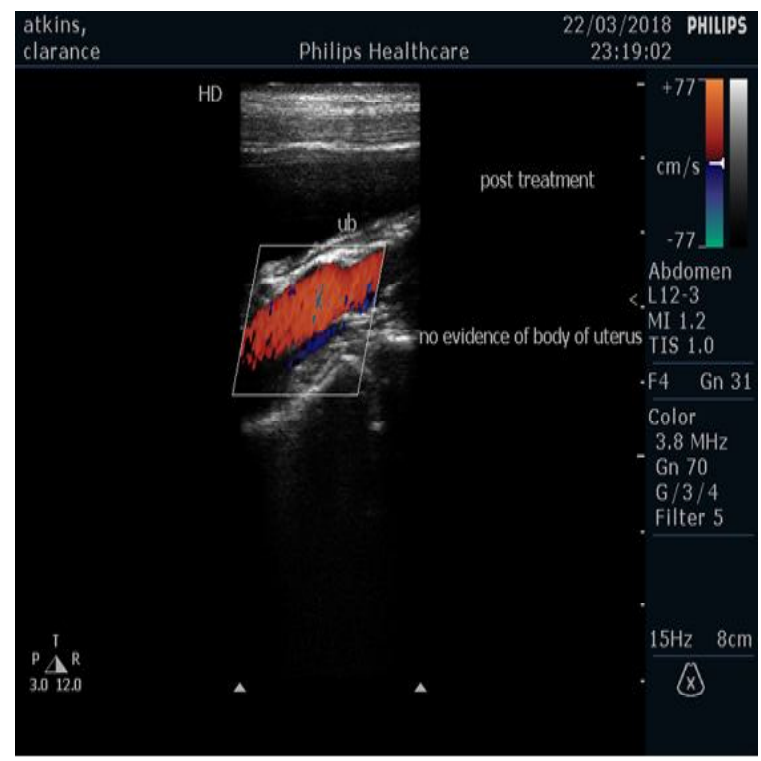

Plate 3: Ultrasonograph of caudal abdomen of a bitch showing no evidence of body of uterus 


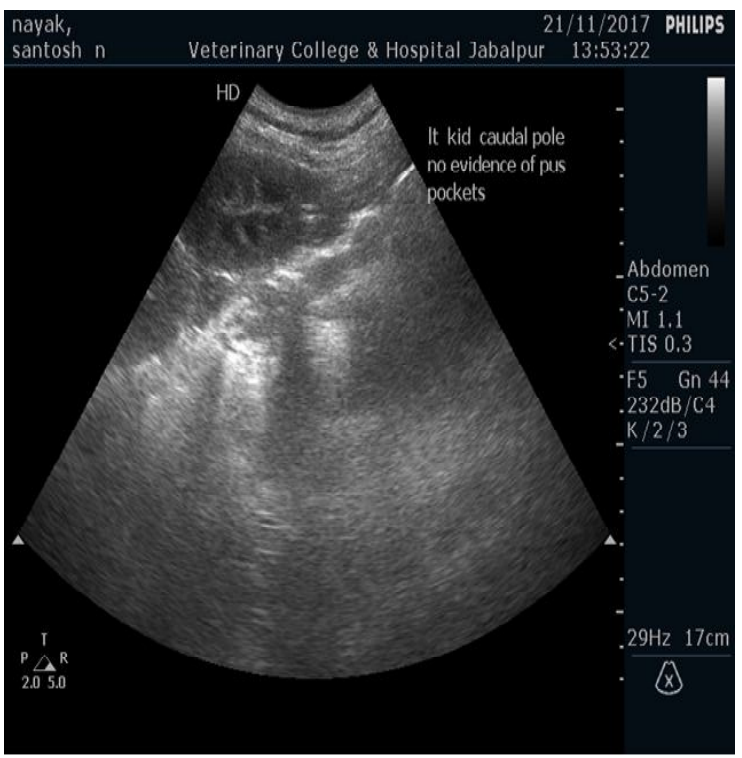

Plate 4: Ultrasonograph of caudal abdomen of a bitch showing no evidence of uterine horn.

normal physiological range (1-2 mg/dl) for clinically healthy dogs (Benjamin,1985).

The mean ALT value (IU/L) in pyometric animals before initiation of treatment in this study was recorded $69.53 \pm 6.25$, $60.50 \pm 7.07$ and $52.20 \pm 8.23$ respectively in $T_{1} T_{2}$ and $\mathrm{Tc}$ groups. After completion of treatment on day 8 , the mean ALT values was decreased in all groups. This indicates better recovery of cases. Similar range of $A L T$ values after ovariohysterectomy in dogs was also recorded by Patil et al. (2013). Lopate (2017) also reported that mild to moderate increase in serum alanine amino transaminase concentrations in animals occasionally encountered may be due to the hepato-cellular damage caused by septicemia and/or due to diminished hepatic circulation and cellular hypoxia in the dehydrated bitch which supports the findings of this study.

There is significantly decrease in mean values of ALP (IU/L) from day 0 to day 8 in $T_{1}$ and $T_{2}$ groups i.e., 117.91士 2.31 to $60.52 \pm 3.67 \mathrm{IU} / \mathrm{L}$ in $\mathrm{T}_{1}$ group, $125.50 \pm 12.4$ to $93.25 \pm 9.09 \mathrm{IU} / \mathrm{L}$ in $\mathrm{T}_{2}$ group. The mean values of ALP in the present study before initiation of treatment were similar to that of study of Shah et al. (2016) in pyometra affected dogs. Mifepristone and dinoprost treated animals showed similar findings $(60.52 \pm 3.67 \mathrm{IU} / \mathrm{L})$ of $\mathrm{ALP}$ after the treatment on day 8 and comparable to the findings of Shah et al. (2016) using similar treatment protocol in canine pyometra. Non hormonal treated animals in the present study showed similar mean values of ALP on day 8 (after treatment) similar to finding of Jena et al. (2013). There was a common tendency for decline in the serum ALP activity with initiation of different treatment regimens in canine pyometra. Sodikoff (1995) have stated that major causes of increased serum ALP activity in dogs are cholestatic liver diseases. These higher findings of ALP reflect hepato-cellular damage in response to toxemia or diminished hepatic circulation due to dehydration induced by pyometra (Verstegen et al., 2008) as in the present study.

In the present study there was significantly decrease in mean serum progesterone in both the hormone treated $\left(T_{1}\right.$ and $T_{2}$ ) groups. The higher pre-treatment mean values of serum progesterone concentration in the present study indicating presence of corpus luteum similar to reports of Gupta et al. (2013). They also found higher serum progesterone in close pyometra than the open ones $(19.97$ \pm 2.88 vs $6.81 \pm 2.59 \mathrm{ng} / \mathrm{ml}$ ) which was associated with presence of multiple cysts and 1-3 CLs simultaneously on the ovaries in bitches with close pyometra and only 1-2 CLs in open pyometra, since CL is the primary source of progesterone in circulation. In this study significantly decrease in serum progesterone post-treatment in antiprogestin and prostaglandin treated $\left(T_{1}\right.$ and $\left.T_{2}\right)$ groups may be due to regression of corpus luteum. It reflects the results of the better recovery with low recurrence of cases after treatment in both the groups.

\section{CONCLUSION}

The therapeutic response using mifepristone with dinoprost tromethamin was found to be the most effective for the treatment of canine pyometra followed by mifepristone and misoprostol protocol (100 vs. $71.43 \%$ ). Mifepristone is an effective medicine of inducing cervical opening in cases of closed pyometra. Higher alteration in the post-treatment values of hematological and haemato-biochemical parameters were observed in both the hormonal treated groups as compared to non-hormonal control group. Nevertheless, in all cases, we only recommend such treatment in bitches with no liver or kidney dysfunction and advise close clinical monitoring during the entire course of treatment.

\section{ACKNOWLEDGEMENT}

The authors are thankful to authorities of College of Veterinary Science and Animal Husbandry, Jabalpur for providing support and necessary facilities to carry out this research.

\section{Conflict of interest}

The authors declare that they have no competing interest.

\section{REFERENCES}

Arunima, C.P. (2013). Studies on haematological, biochemical, hormonal and histopathological parameters in pyometra of bitches. M.V.Sc. thesis (Veterinary Gynaecology and Obstetrics), Karnataka Veterinary, Animal and Fisheries Science University, Bidar.

Benjamin, M.M. (1985). Outline of Veterinary Clinical Pathology. $3^{\text {rd }}$ Edn., Kalyani Publishers, New Delhi. pp 5-316.

Bigliardi, E., Parmigiani, E., Cavirani, S., Luppi, A., Bonati, L. and Corradi, A. (2004). Ultrasonography and cystic hyperplasia-pyometra complex in the bitch. Reproduction in Domestic Animals. 39: 136-140. 
Fayrer-Hosken, R.A., Mahaffey, M., Miller-Liebl, D. and Caudle, A.B. (1991). Early diagnosis of canine pyometra using ultrasonography. Veterinary Radiology. 32(6): 287-289.

Fieni, F. (2006). Clinical evaluation of the use of aglepristone, with or without cloprostenol, to treat cystic endometrial hyperplasiapyometra complex in bitches. Theriogenology. 66: 15501556.

Fransson, B.A., Lagerstedt, A.S., Bergstrom,A., Hagman, R., Park, J.S., Chew, B.P., Evans, .A., Ragle, C.A. (2007). C-reactive protein, tumor necrosis factor- $\alpha$ and interleukin- 6 in dogs with pyometra and SIRS. J. Vet. Emerg. Critical Care. 17: 373-381.

Gandotra, V.K., Singla, V.K., Kochar, H.P.S., Chauhan, F.S. and Dwivedi, P.N. (1994). Haematological and bacteriological studies in canine pyometra. Indian Veterinary Journal. 71(8): 816818.

Gupta, A.K., Dhami, A.J., Patel, S.B. and Shah, R.G. (2013). Evaluation of clinical biochemistry of blood in bitches affected with pyometra. Indian Journal of Animal Reproduction. 34(1): 26-30.

Hagman, R. and Kuhn, I. (2002). Escherichia coli strains isolated from the uterus and urinary bladder of bitches suffering from pyometra: Comparison by restriction enzyme digestion and pulsed-field gel electrophoresis. Veterinary Microbiology. 84: 143-153.

Hagman, R., Kindah, I.H. and Lagerstedt, A.S. (2006). Pyometra in bitches induces elevated plasma endotoxin and prostaglandin $\mathrm{F}_{2 a}$ metabolite levels. Acta Veterinaria Scandinavica. 47: 55-68.

Hiene, R., Moe, L. and Molmen, G. (2001). Calculation of urinary enzyme excretion, with renal structure and function in dogs with pyometra. Research in Veterinary Science. 70: 129-137.

Hoffmann, B., Lemmer, W., Bostedt, H.and Failing, K. (2000). Application of the antiprogestin aglepristone for the conservative treatment of pyometra in the dog. Tierarztl Prax. 28: 323329.

Jena, B., Rao, K.S., Reddy, K.B.P. and Raghavender. (2013). Comparative efficacy of various therapeutic protocols in the treatment of pyometra in the bitches. Veterinarni Medicina. 58(5): 271-276.

Kirby R. (2017). An introduction to SIRS and the rule of 20. In: Kirby $\mathrm{R}$, Linklater $\mathrm{A}$, editors. Monitoring and intervention for the critically ill small animal. Ames (IA): Wiley Blackwell. p. 1-8.

Lopate C. (2017). Pyometra, cystic endometrial hyperplasia (hydrometra, mucometra, hematometra). In: Greco DS, Davidson AP, editors. Blackwell's five-minute veterinary consult clinical companion, small animal endocrinology and reproduction. Hoboken (NJ): Wiley-Blackwell. p. 53-62.

Meher, J., Patil, A.D. Sahatpure, S.K., Bhojne, G.R. and Patil, D.V. (2018). Efficacy of cloprostenol and cabergoline therapy in cystic endometrial hyperplasia. Indian Journal of Canine Practice. 10(1): 24-28.
Melih, U., Tek, C., Gunduzi, M.C., Sabuncu, A., Bagcigil, F.A. and Bakirel, T. (2012). Optimum timing for operation in bitches with pyometra related to endotoxemia. Turkish Journal of Veterinary and Animal Science. 36(1): 35-42.

Noakes, D.E., Dhaliwal, G.K. and England, G.C. (2001). Cystic endometria hyperplasic/ pyometra in dogs: a review of the causes and pathogenesis. Journal of Reproduction and Fertility, Suppl. 57: 395-406.

Nyland, T.G. and Mattoon, J.S. (2002). Ovaries and Uterus. In: Small Animal Diagnostic Ultrasound. [Kersey, R. (ed.)]. $2^{\text {nd }}$ Edn., Saunders. pp 231-249.

Patil, A.R., Swamy, M., Chandra, A. and Jawre, S. (2013). Clinicohaematological and serum biochemical alterations in pyometra affected bitches. African Journal of Biotechnology. 12(13): 1564-1570.

Pollard R and Hecht S. (2015). Female Reproductive Tract. In: Atlas of small animal ultrasonography. Penninck D, d' Anjou MA, editors. $2^{\text {nd }}$ ed. Hoboken: Wiley Blackwell. p. 403-21.

Renukaradhya, G.J. (2011). Studies on treatment of pyometra in bitches with antiprogestins. Doctor of Philosophy thesis (Veterinary Gynaecology and Obstetrics), Karnataka Veterinary, Animal and Fisheries Science University, Bidar.

Sevelius, E., Tidholm, A. and Thoren-Tolling, K. (1990). Pyometra in the dog. Journal of the American Animal Hospital Association. 26: 33-38.

Shah, M.A., Pande, N., Shah, I.A., Agrawal, R., Sharma, U. and Ghuman, S.P.S. (2016). Treatment of pyometra in female dogs using prostaglandin- $\mathrm{F}_{2 a}$ with and without antiprogestin (mifepristone). Indian Journal of Animal Reproduction, 37(1): 23-26.

Smith, F.O. (2006). Canine pyometra. Theriogenology. 66: 610-612. Sodikoff, C.H. (1995). Laboratory Profiles of Small Animal Diseases: A Guide to Laboratory Diagnosis. $2^{\text {nd }}$ Edn., Mosby Year Book. 435 p.

Trasch, K., Wehrend, A. and Bostedt, H. (2003). Follow-up examinations of bitches after conservative treatment of pyometra with the antigestagen aglepristone. Journal of Veterinary Medicine: A Physiology, Pathology and Clinical Medicine. 50: 375-379.

Verstegen, J., Dhaliwal, G. and Verstegen-Onclin, K. (2008). Mucometra, cystic endometrial hyperplasia and pyometra in the bitch: Advances in treatment and assessment of future reproductive success. Theriogenology. 70: 364-374.

Voges, A.K. and Neuwirth, L. (1996). Ultrasound diagnosis-cystic uterine hyperplasia. Veterinary Radiology and Ultrasound, 37: 131-132.

Wheaton, G., Johnson, L., Parker, J. and Kneller, K. (1989). Results and complications of surgical treatment of pyometra- $A$ review of 80 cases. Journal of American Animal Hospital Association. 25: 563-568. 